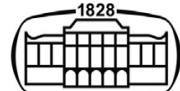

AKADÉMIAI KIADÓ

\section{Acta Veterinaria Hungarica}

$69(2021) 3,256-265$

DOI:

$10.1556 / 004.2021 .00031$

(c) 2021 The Author(s)

\section{RESEARCH ARTICLE}

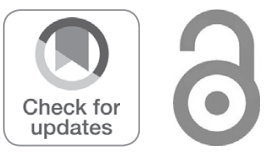

\title{
The role of selenium and vitamin $E$ in a Transylvanian enzootic equine recurrent rhabdomyolysis syndrome
}

\author{
CSABA ATTILA KÓSA ${ }^{1 \dagger}$, KRISZTINA NAGY ${ }^{2}$, OTTÓ SZENCI ${ }^{2}$, \\ BOGLÁRKA BASKA-VINCZE ${ }^{3}$, EMESE ANDRÁSOFSZKY ${ }^{3}$, \\ RÓBERT SZÉP ${ }^{4,5,6}$, ÁGNES KERESZTESI ${ }^{4,5,6}$, \\ MIRCEA MIRCEAN ${ }^{7}$, MARIAN TAULESCU ${ }^{7}$ and \\ ORSOLYA KUTASI ${ }^{2,3,8 *}$
}

\author{
${ }^{1}$ Veterinary Cabinet Uz Bence SRL, Szentegyháza (Vlahita), Romania \\ ${ }^{2}$ MTA-SZIE Large Animal Clinical Research Group, Üllő, Hungary \\ ${ }^{3}$ Department of Animal Breeding, Nutrition and Laboratory Animal Science, University of \\ Veterinary Medicine Budapest, István utca 2, H-1078, Budapest, Hungary \\ ${ }^{4}$ Doctoral School of Chemistry, Faculty of Natural Sciences, University of Pécs, Pécs, Hungary \\ ${ }^{5}$ Department of Bioengineering, Faculty of Economics, Socio-Human Sciences and Engineering, \\ Sapientia Hungarian University of Transylvania, Miercurea Ciuc, Romania \\ ${ }^{6}$ Institute for Research and Development for Hunting and Mountain Resources, Miercurea Ciuc, \\ Romania \\ ${ }^{7}$ Faculty of Veterinary Medicine, University of Agricultural Sciences and Veterinary Medicine of \\ Cluj-Napoca, Cluj-Napoca, Romania \\ ${ }^{8}$ University Equine Hospital, Department/Hospital for Companion Animals and Horses, University \\ of Veterinary Medicine Vienna, Vienna, Austria
}

Received: 10 September 2020 • Accepted: 21 July 2021

Published online: 7 September 2021

\begin{abstract}
A severe form of recurrent exertional rhabdomyolysis occurs enzootically in a well-defined region of Transylvania, Harghita county. At the highest lying two settlements (more than $800 \mathrm{~m}$ above sea level), the prevalence of equine rhabdomyolysis is between 17 and 23\%, while in the neighbouring villages in the valley it is less than $2 \%$. The objective of our study was to clarify the role of selenium and vitamin $\mathrm{E}$ in the high prevalence of rhabdomyolysis in that region. Soil and hay samples were collected from each area to evaluate mineral content. Ten horses from the non-affected and 20 horses from the affected area were tested for serum selenium, vitamin E, glutathione peroxidase (GSH-Px), muscle enzymes, lactate and electrolytes. Hay samples collected from the affected area had lower selenium content. Horses in the affected regions had significantly lower serum selenium $(P=0.006)$ and GSH-Px levels than animals living in the non-affected regions. A good correlation between erythrocyte GSH-Px and serum selenium concentration could be demonstrated $(r=0.777, P<0.001)$. Serum vitamin E levels were low independently of the origin of the horse. Based on our results, selenium deficiency possibly has a role in the Transylvanian enzootic equine recurrent rhabdomyolysis syndrome.
\end{abstract}

${ }^{\dagger}$ PhD student at the University of Veterinary Medicine Budapest, Hungary.

\section{KEYWORDS}

equine, rhabdomyolysis, selenium, vitamin $\mathrm{E}$

* Corresponding author.

E-mail: kutasi.orsolya@univet.hu; korbacskao@staff.vetmeduni.ac.at

A severe form of recurrent rhabdomyolysis occurs enzootically in a well-defined region of Transylvania, Harghita county. In the two highest lying settlements (more than $800 \mathrm{~m}$ above 
sea level) the prevalence of equine rhabdomyolysis is between 17 and $23 \%$, while in the neighbouring villages in the valley it is less than $2 \%$ (Kósa et al., 2015). This specific rhabdomyolysis syndrome is associated with exertion in most cases, but clinical signs also occur sporadically in horses not doing any intense exercise (Kósa et al., 2018). Clinical signs include painful, swollen muscles, stiffness, weakness, rhabdomyolysis, myoglobinuria, and in more severe cases dysphagia and recumbency also occur. In most affected horses the episodes are recurrent, while in chronic cases muscle atrophy is observed (Kósa et al., 2018).

Determining the underlying cause of rhabdomyolysis is complicated due to the fact that a given disorder may have variable clinical signs while myopathies of different aetiology may show a similar clinical picture (Ludvikova et al., 2005b, 2007; Valberg, 2018). Beyond a probable hereditary factor, there does not seem to be a single cause that triggers recurrent rhabdomyolysis in horses. Among these factors we can mention the overfeeding of non-structural carbohydrates, poor conditioning or fitness, sudden increase of workload, electrolyte or mineral imbalances, or imbalance of certain hormones (Valentine, 2005; Radostits et al., 2014). Among dietary factors, the main theory that dominates in the aetiology of recurrent rhabdomyolysis is selenium/ vitamin E deficiency (Aleman, 2008; Streeter et al., 2012).

There are several equine muscular disorders associated with vitamin $\mathrm{E}$ and/or selenium deficiency. White muscle disease (WMD) is the main clinical manifestation of selenium and, to a lesser extent, vitamin E deficiency in horses. WMD is also often associated with inappropriate physical exercise or increased dietary supply of unsaturated lipids (Lofstedt, 1997). It has been reported that foals younger than one year prevail among horses affected by WMD (Lofstedt, 1997; Harris, 1998; Valberg, 2002; Streeter et al., 2012) but some authors have found a higher percentage of adult horses (Ludvikova et al., 2005b).

Yellow fat disease, also named polymyositis or muscular dystrophy, can also be associated with nutritional selenium and/or vitamin E deficiency (Foreman et al., 1986). A clear relationship between exertional rhabdomyolysis (tying-up syndrome) and vitamin E or selenium deficiency has not yet been described in horses (Valentine, 2005) but the important role of selenium in these myopathies has been recognised previously (Gomez et al., 2015). Nevertheless, these conditions have been treated by aggressive antioxidant therapy including vitamin $\mathrm{E}$, selenium, and vitamin C (Kirschvink et al., 2008). In the recently described vitamin E-deficient myopathy, horses may develop clinical signs related solely to muscle atrophy and weakness (Bedford et al., 2013). Selenium deficiencies in horses have been determined geographically and apparently they depend on the chemical composition of the soil in areas used for pasture (Wyganowska et al., 2017). A deficiency of this element has been noted in horses that graze on pastures with selenium-deficient soil or whose diet is based on feed from such areas which is not supplemented with organic or inorganic selenium (Janicki et al., 2000; Wyganowska et al., 2017). The selenium status of animals can be evaluated by the direct determination of selenium concentration in the blood or indirectly by derivation from the measurements of glutathione peroxidase (GSH-Px) activity (Ludvikova et al., 2005a).

Depending on the availability of grass and fresh hay, a horse can consume less than the daily recommended amount of vitamin E. Horses without access to green forage should be supplemented with vitamin $\mathrm{E}$ on a daily basis (Finno and Valberg, 2012). In horses, plasma and adipose tissue concentrations as well as plasma, hepatic and muscle concentrations of vitamin $\mathrm{E}$ are linearly correlated (Finno and Valberg, 2012), thus one plasma sample would be enough to gain insight into the animal's overall vitamin $\mathrm{E}$ supply status (adequate, marginal, or deficient).

The objective of this study was to clarify the nutritional background of the high prevalence of rhabdomyolysis in a specific Transylvanian geographical region, focussing on the role of vitamin $\mathrm{E}$ and selenium.

\section{MATERIALS AND METHODS}

The study was approved by the Bioethics Commission of the Faculty of Veterinary Medicine Cluj-Napoca (175/ 18.09.2019).

The study was conducted in four villages of Transylvania: two villages from the affected region of Szentegyháza and Kápolnásfalu (high villages: $\mathrm{HV}$ ) and two villages in the non-affected neighbouring valley region (valley villages: VV, Lövéte and Homoródfürdö). In the HV areas there were approx. 800 horses and in the VV area the population was smaller, approx. 260 horses. Altogether 30 horses were randomly selected for the study: 20 animals in the HV (mean age \pm SD: $8.5 \pm 4.4$ years; 7 females and 13 males) and 10 horses in the VV area $(9 \pm 3.5$ years, 5 females and 5 males). The number of samples was estimated with the help of the 'www.epitools.ausvet.com' with the odds ratio and expected number of cases based on previous studies (Kósa et al., 2015). The selection was performed on the patient database of the treating veterinarian (the first author) according to the selection criteria. If the owner did not give his/her consent to the examinations at that time, another horse was randomly selected.

All horses were of a similar local warmblood breed with a cold-blooded type phenotypic influence. The enrolment criteria were the following: age between 3 and 20 years and no acute clinical signs of any disease at the time of sampling. All these animals were working equids taking part in the seasonal forestry works and were kept under similar conditions in individual stalls. Their daily ration consisted of $2.5 \%$ DMI of locally harvested pasture hay, to which no concentrate or mineral, electrolyte or vitamin supplement was added. The horses had access to water from local water sources twice a day. All of them regularly took up the normally required amount of $40-60 \mathrm{~mL}$ water $/ \mathrm{kg}$ of body weight.

Clinical signalment and history of the horses were taken where we noted that a particular horse had been previously affected by rhabdomyolysis. 
Blood was collected from the jugular vein into sterile test tubes with no anticoagulant and it was kept at room temperature until centrifugation. Within $4 \mathrm{~h}$ these samples were used to determine serum vitamin E, selenium, muscle enzymes including creatine kinase $(\mathrm{CK})$, aspartate transaminase (AST) and lactate dehydrogenase (LDH), lactate and some electrolyte levels ( $\mathrm{Na}, \mathrm{K}, \mathrm{Cl}, \mathrm{Ca}, \mathrm{P})$. Whole blood $(2 \mathrm{~mL})$ collected into lithium-heparin tubes and centrifuged within $1 \mathrm{~h}$ after sampling was used to determine the activity of GSH-Px. Samples were frozen after centrifugation and kept at $-20{ }^{\circ} \mathrm{C}$ until processing. Blood enzymes, lactate and electrolyte parameters were evaluated spectrophotometrically by using commercially available test kits with a chemistry analyser (Olympus AU640, Beckman Coulter, Hamburg, Germany). Vitamin E was assayed by a modified high-performance liquid chromatography (HPLC; Praxislab Ltd, Budapest, Hungary) with fluorescence detection (Che et al., 2015). Selenium analysis of the serum was performed by atomic spectroscopy (Optima 8300 ICP-OES Spectrometer, PerkinElmer, USA) and GSH-Px enzymatic activity in erythrocytes was determined based on the method of Paglia and Valentine (1967) (Screen-Master plus, MedWoW Ltd, Nicosia, Cyprus) supplied by Biochemical Systems International. Samples were taken in the spring when animals had only a low to moderate workload.

We collected soil samples of $30 \mathrm{~cm}$ depth from the pastures of both regions ( 3 samples from the VV and 4 samples from the $\mathrm{HV}$ region) to evaluate the macro- and micromineral content ( $\mathrm{Ca}, \mathrm{K}, \mathrm{Mg}, \mathrm{Na}, \mathrm{P}, \mathrm{S}, \mathrm{Cu}, \mathrm{Zn}, \mathrm{Mn}, \mathrm{Mo}, \mathrm{Fe}$, $\mathrm{Pb}, \mathrm{Cd}, \mathrm{Se}$ ) of the geographic area. Sampling of the pasture hay bales for nutrient analysis and determining the macroand micromineral content ( $\mathrm{Ca}, \mathrm{K}, \mathrm{Mg}, \mathrm{Na}, \mathrm{P}, \mathrm{S}, \mathrm{Cu}, \mathrm{Zn}, \mathrm{Mn}$, $\mathrm{Mo}, \mathrm{Fe}, \mathrm{Pb}, \mathrm{Cd}, \mathrm{Se}$ ) were carried out by selecting 16 representative bales in the $\mathrm{HV}$ area and 13 bales in the $\mathrm{VV}$ area and collecting two core and two circumference samples from each. All samples from each bale were put in a bucket and homogenised. Hay analysis included the determination of dry matter (DM), ash, ether extract, crude protein (CP), neutral detergent fibre (NDF) and acid detergent fibre (ADF). These measurements were carried out according to relevant ISO standards (ISO 5983 - 16472) 1-6. Digestible energy (DE) was estimated from the chemical composition. Mineral content analysis of the soil, water and forage was performed by atomic spectroscopy (Optima 8300 ICP-OES Spectrometer, PerkinElmer, USA).

The role of water sources in selenium availability and homoeostasis was also examined. We tested all potable water present in the observed area (8 representative samples in the $\mathrm{HV}$ area and 8 samples in the VV area) to see whether the water samples contained any dissolved organic matter, fulvic acid (FA) and humic acid (HA). The UV-VIS spectrum and absorbance of the filtered water samples $(5-8 \mu \mathrm{m}$ filter paper) were examined with a spectrophotometer (SP-UV 1100 Spectrometer, DLab Scientific Inc., California, USA) between 190 and $1,100 \mathrm{~nm}$ wavelength according to the International Humic Substance Society (IHSS) standard. We also measured $\mathrm{pH}$, total dissolved solids (TDS) and electric conductivity (EC) of the water samples.
All analyses were performed in R 3.4.4. (R Development Core Team, the $\mathrm{R}$ Project for Statistical Computing, USA). The significance level was set at $P<0.05$. Difference in the occurrence of the disease between $\mathrm{HV}$ and $\mathrm{VV}$ was analysed by Fisher's exact test (SPSS). In order to find out the differences between the two habitats, we analysed their hay and soil parameters. For further analysis we created four groups according to habitat and disease (HV with disease: $n=12$, HV without disease: $n=8, \mathrm{VV}$ with disease: $n=1$, and VV without disease: $n=9$ ).

Differences between groups regarding age and sex were analysed by linear models. We examined the measured blood parameters of horses looking for differences in three groups (as among VV horses only one horse was showing disease and we excluded that horse/group from this analysis). The measured values were mainly non-normally distributed. Therefore, generalised linear models for nonnormally distributed values were applied for all the measured parameters of hay and soil to test for significant differences between habitats, and for all the measured blood parameters to test for significant differences between the three groups.

Correlations among GSH-Px, selenium concentration, vitamin $\mathrm{E}, \mathrm{AST}, \mathrm{LDH}$ and $\mathrm{CK}$ were tested by correlation tests (Spearman, IBM SPSS Statistics 20 Documentation, USA). The results of water samples originating from the two different regions of $\mathrm{VV}$ and $\mathrm{HV}$ areas were compared by ANOVA.

\section{RESULTS}

In the HV region 8 out of 20 horses got the disease only once and 8 did more than once, while in the VV area 1 out of 10 horses got the disease twice recurrently. The chance of getting the disease was 18.7 times higher in the HV than in the $\mathrm{VV}$ area. This fact was also confirmed by the Fisher test $(P=0.005)$.

Analysis of soil samples collected at both sites of $\mathrm{HV}$ and VV revealed low selenium levels of $0.46 \pm 0.33 \mathrm{ppm}$ and 0.41 $\pm 0.12 \mathrm{ppm}$, respectively. The arithmetic mean was established as a pedogeochemical background and significant differences related to it were the higher levels of $\mathrm{Ca}$ $(+60.4 \%), \mathrm{Cu}(+70.1 \%), \mathrm{Zn}(+75 \%), \mathrm{Cd}(+68.2 \%), \mathrm{Fe}$ $(+45.2 \%), \mathrm{Mn}(+44.2 \%)$ and $\mathrm{Na}(+34.1 \%)$ in the $\mathrm{HV}$ areas.

The results of hay analysis are presented in Tables 1 and 2. There were no significant differences between hay samples originating from the $\mathrm{HV}$ and $\mathrm{VV}$ areas in terms of $\mathrm{CP}$, ash, ether extract, ADF, NDF and DE.

The content of selenium was below our detection limit of $0.05 \mathrm{ppm}$ in all $\mathrm{HV}$ samples and it was $0.65 \mathrm{ppm}$ in VV hay samples. Significant percentage differences were the higher iron $(+45.2 \%)$ and lower manganese $(-111.4 \%)$ values in the samples from the VV areas. Relatively higher mineral values (calcium $22.5 \%$, potassium $21.7 \%$, magnesium $14.6 \%$, sodium $6.9 \%$, and phosphorus $4.0 \%$ higher) related to the mean of the statistical population were measured in the VV hay samples. 


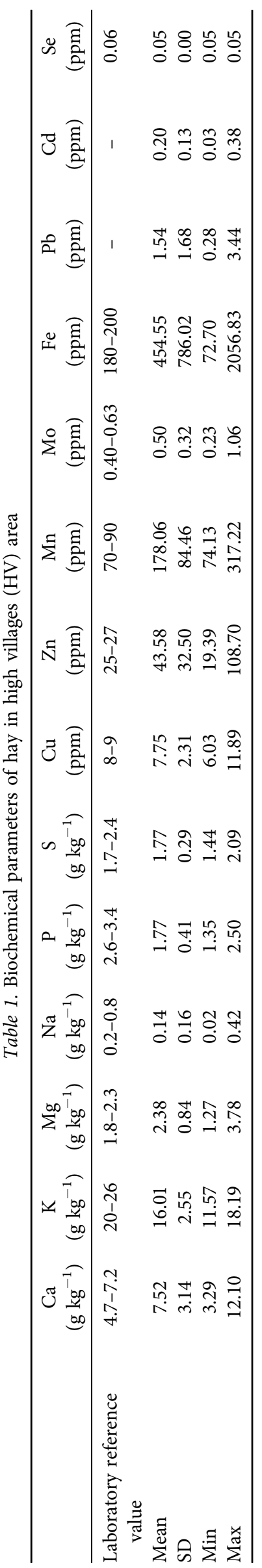

The results of biochemical parameters measured from the serum samples of horses are shown in Tables 3 and 4. Marked selenium deficiency was observed in all horses of the HV region $\left(30.2 \pm 19.2 \mu \mathrm{g} / \mathrm{L}^{-1}\right)$. Serum selenium was significantly lower in $\mathrm{HV}$ affected horses compared to VV non-affected horses $(P=0.006)$ and it was significantly lower in HV nonaffected compared to VV non-affected horses $(P<0.001)$ (Fig. 1). GSH-Px was significantly lower in HV affected horses $\left(129.8 \pm 33.7 \mu \mathrm{kat} \cdot 1^{-1}\right)$ compared to $\mathrm{VV}$ non-affected horses $\left(300.4 \pm 35.9 \mu \mathrm{kat} \cdot \mathrm{l}^{-1}\right)(P<0.001)$ (Fig. 2).

Spearman correlation between erythrocyte GSH-Px and serum selenium concentration indicated a high correlation ( $r=0.777, P<0.001)$. Analysing the two sampling areas $(\mathrm{HV}, \mathrm{VV})$ separately, the correlation was significantly lower $(r=0.365, P=0.364)$ in the affected group (HV) and there was no correlation in the case of the non-affected horses (VV) $(r=0.300)$. This was also supported by the regression analysis performed for $\mathrm{HV}$ and VV horses (Fig. 3). The significant culmination of the two statistical populations could be seen in this case, as well. The fact that VV horses were more inhomogeneous was also noted.

The level of vitamin $\mathrm{E}$ was very low in all animals: $0.45 \pm$ $0.17 \mu \mathrm{g} / \mathrm{ml}^{-1}, 0.57 \pm 0.20 \mu \mathrm{g} \cdot \mathrm{ml}^{-1}$ and $0.43 \pm 0.38 \mu \mathrm{g} / \mathrm{ml}^{-1}$ in the $\mathrm{HV}$ affected, HV non-affected and VV groups, respectively. A significant positive correlation $(r=0.66)$ between serum selenium and vitamin $\mathrm{E}$ concentrations was demonstrated.

There was no significant difference regarding the activity levels of muscle enzymes in any group of horses. All muscle enzymes were increased in more than $80 \%$ of horses independently of their origin and history of being affected or not.

There was no significant difference among groups regarding sodium, chloride, calcium or phosphorus concentrations. Lactate concentration was significantly lower in VV non-affected horses compared to HV affected horses ( $P$ $=0.022)$. These observations are also supported by the boxplots shown in Fig. 4.

We did not find any correlation between GSH-Px or selenium and $\mathrm{LDH}$ or CK enzymes, but there was a negative correlation between GSH-Px and AST $(r=-312)$, and GSHPx and lactate $(r=-350)$.

In order to evaluate the water parameters (Table 5), the $f$ test was carried out for $\mathrm{pH}, \mathrm{EC}$ and TDS. The results showed that the calculated $f$ values were higher than the $f$ critical values, therefore the variance of the water is unequal. To verify if the results obtained with the $f$ test are correct, the $t$ test (two-sample assuming unequal variances) was applied.

The analysis of water samples did not reveal any dissolved organic matter in any of the examined areas that could influence selenium absorption. According to the results, the mean values of the two types of water sources were equal, hence the calculated $t$ values were lower than the critical $t$ values for $\mathrm{pH}$, TDS and EC. Analysis of variance (ANOVA, Table 6) showed that there were no significant differences between the samples and the water types in the above parameters. 
Table 2. Biochemical parameters of hay in valley villages (VV) area

\begin{tabular}{|c|c|c|c|c|c|c|c|c|c|c|c|c|c|c|}
\hline & $\begin{array}{c}\mathrm{Ca} \\
\left(\mathrm{g} \mathrm{kg}^{-1}\right)\end{array}$ & $\begin{array}{c}\mathrm{K} \\
\left(\mathrm{g} \mathrm{kg}^{-1}\right)\end{array}$ & $\begin{array}{c}\mathrm{Mg} \\
\left(\mathrm{g} \mathrm{kg}^{-1}\right)\end{array}$ & $\begin{array}{c}\mathrm{Na} \\
\left(\mathrm{g} \mathrm{kg}^{-1}\right)\end{array}$ & $\begin{array}{c}\mathrm{P} \\
\left(\mathrm{g} \mathrm{kg}^{-1}\right)\end{array}$ & $\begin{array}{c}\mathrm{S} \\
\left(\mathrm{g} \mathrm{kg}^{-1}\right)\end{array}$ & $\begin{array}{c}\mathrm{Cu} \\
(\mathrm{ppm})\end{array}$ & $\begin{array}{c}\mathrm{Zn} \\
(\mathrm{ppm})\end{array}$ & $\begin{array}{c}\mathrm{Mn} \\
(\mathrm{ppm})\end{array}$ & $\begin{array}{c}\mathrm{Mo} \\
(\mathrm{ppm})\end{array}$ & $\begin{array}{c}\mathrm{Fe} \\
(\mathrm{ppm})\end{array}$ & $\begin{array}{c}\mathrm{Pb} \\
(\mathrm{ppm})\end{array}$ & $\begin{array}{c}\mathrm{Cd} \\
(\mathrm{ppm})\end{array}$ & $\begin{array}{c}\mathrm{Se} \\
(\mathrm{ppm})\end{array}$ \\
\hline Laboratory reference value & $4.7-7.2$ & $20-26$ & $1.8-2.3$ & $0.2-0.8$ & $2.6-3.4$ & $1.7-2.4$ & $8-9$ & $25-27$ & $70-90$ & $0.40-0.63$ & $180-200$ & - & - & 0.06 \\
\hline Mean & 10.7 & 17.4 & 2.6 & 0 & 1.3 & 1.8 & 6.7 & 32.9 & 137 & 0.4 & 366.9 & 0.4 & 0.2 & 0.1 \\
\hline SD & 2.9 & 3.4 & 0.8 & 0 & 0.1 & 0.2 & 0.1 & 7.4 & 40.9 & 0.2 & 179.3 & 0.3 & 0.1 & 0 \\
\hline Min & 7.8 & 15.4 & 1.8 & 0 & 1.1 & 1.6 & 6.6 & 26 & 109.1 & 0.2 & 175.2 & 0.2 & 0.2 & 0.1 \\
\hline Max & 13.7 & 21.4 & 3.5 & 0 & 1.4 & 2 & 6.8 & 40.7 & 183.9 & 0.5 & 530.6 & 0.7 & 0.4 & 0.1 \\
\hline
\end{tabular}

Table 3. Biochemical parameters from serum samples in horses from the HV area

\begin{tabular}{|c|c|c|c|c|c|c|c|c|c|c|c|}
\hline & $\begin{array}{c}\text { AST } \\
\left(\mathrm{U} \mathrm{L}^{-1}\right)\end{array}$ & $\begin{array}{c}\mathrm{LDH} \\
\left(\mathrm{U} \mathrm{L}^{-1}\right)\end{array}$ & $\begin{array}{c}\mathrm{CK} \\
\left(\mathrm{U} \mathrm{L}^{-1}\right)\end{array}$ & $\begin{array}{c}\text { Lactate } \\
\left(\mathrm{mmol} \mathrm{L}^{-1}\right)\end{array}$ & $\begin{array}{c}\mathrm{GPx} \\
\left(\mu \mathrm{g} \mathrm{L}^{-1}\right)\end{array}$ & $\begin{array}{c}\mathrm{Se} \\
\left(\mathrm{Ug} \mathrm{L}^{-1}\right)\end{array}$ & $\begin{array}{c}\text { E-vit } \\
\left(\mathrm{mg} \mathrm{L}^{-1}\right)\end{array}$ & $\begin{array}{c}\mathrm{Na} \\
\left(\mathrm{mmol} \mathrm{L}^{-1}\right)\end{array}$ & $\begin{array}{c}\mathrm{P} \\
\left(\mathrm{mmol} \mathrm{L}^{-1}\right)\end{array}$ & $\begin{array}{c}\mathrm{Cl} \\
\left(\mathrm{mmol} \mathrm{L}^{-1}\right)\end{array}$ & $\begin{array}{c}\mathrm{Ca} \\
\left(\mathrm{mmol} \mathrm{L}^{-1}\right)\end{array}$ \\
\hline Laboratory reference values & $100-370$ & $80-650$ & $20-350$ & $0.5-2.0$ & $>200$ & $100-200$ & $1.00-5.00$ & $132-146$ & $0.9-1.8$ & $89-108$ & $2.5-3.6$ \\
\hline Mean & 841.86 & $1,350.80$ & 789.26 & 3.50 & 129.79 & 43.53 & 0.45 & 135.24 & 0.97 & 99.29 & 2.93 \\
\hline SD & 638.26 & $1,069.56$ & 940.85 & 0.69 & 34.97 & 46.16 & 0.17 & 2.99 & 0.21 & 1.41 & 0.14 \\
\hline Min & 312.30 & 778.80 & 319.10 & 2.79 & 70.00 & 10.39 & 0.10 & 130.90 & 0.72 & 95.80 & 2.69 \\
\hline $\operatorname{Max}$ & $2,750.90$ & $4,977.30$ & $3,862.30$ & 5.39 & 202.00 & 186.00 & 0.80 & 141.00 & 1.57 & 102.00 & 3.22 \\
\hline
\end{tabular}

AST: aspartate transaminase

LDH: lactate dehydrogenase.

CK: creatine kinase. 

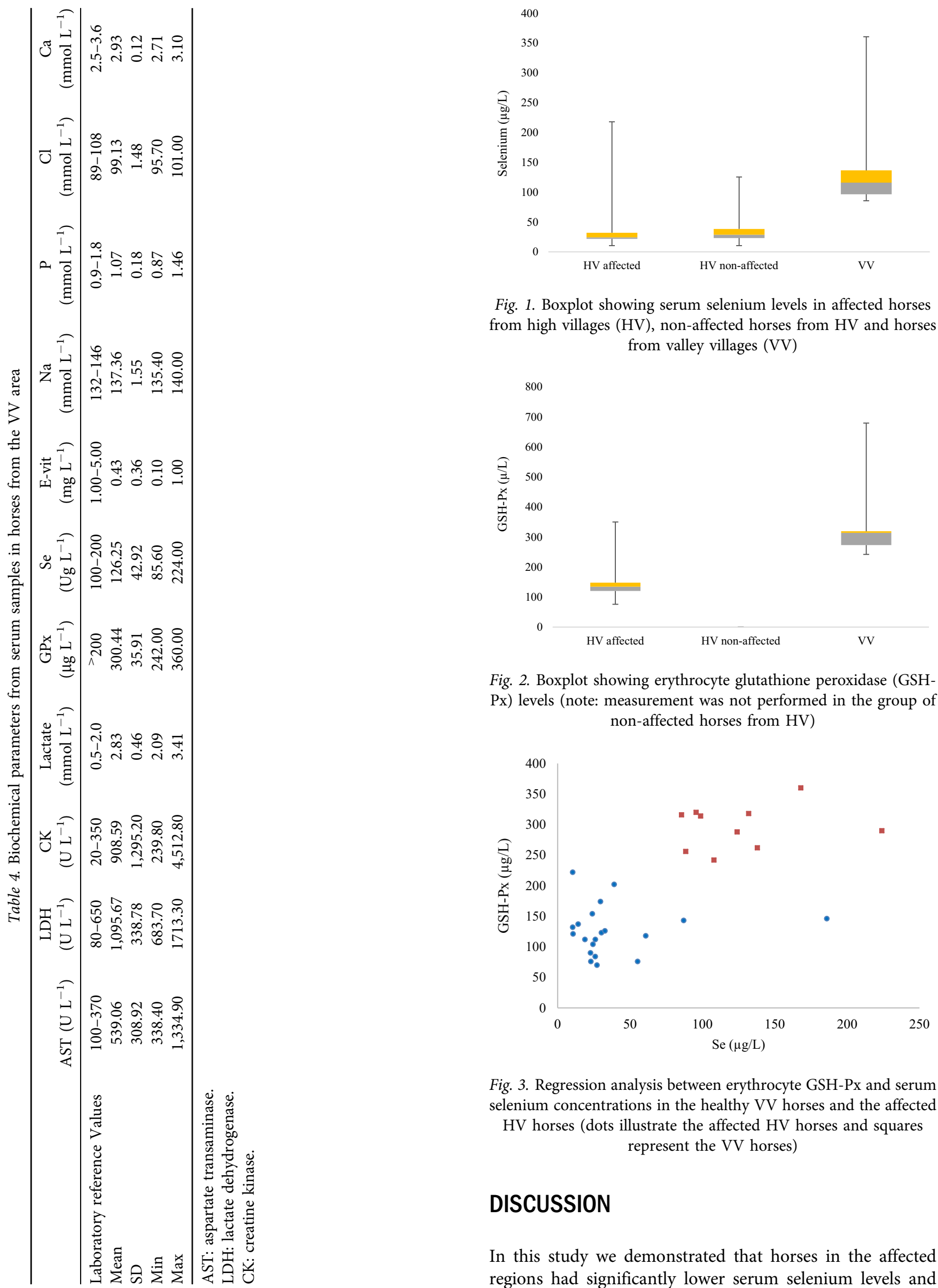

Fig. 1. Boxplot showing serum selenium levels in affected horses from high villages (HV), non-affected horses from HV and horses from valley villages $(\mathrm{VV})$

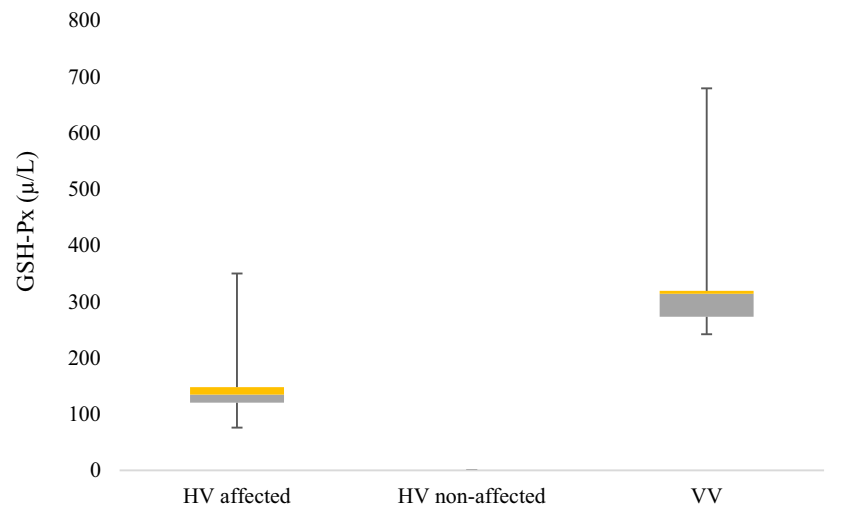

Fig. 2. Boxplot showing erythrocyte glutathione peroxidase (GSH$\mathrm{Px}$ ) levels (note: measurement was not performed in the group of non-affected horses from HV)

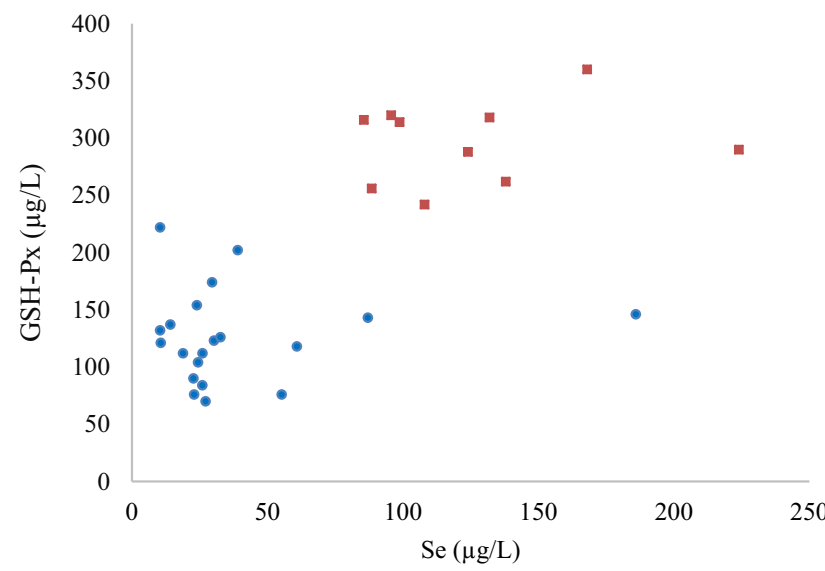

Fig. 3. Regression analysis between erythrocyte GSH-Px and serum selenium concentrations in the healthy VV horses and the affected HV horses (dots illustrate the affected HV horses and squares represent the VV horses)

\section{DISCUSSION}

In this study we demonstrated that horses in the affected regions had significantly lower serum selenium levels and 


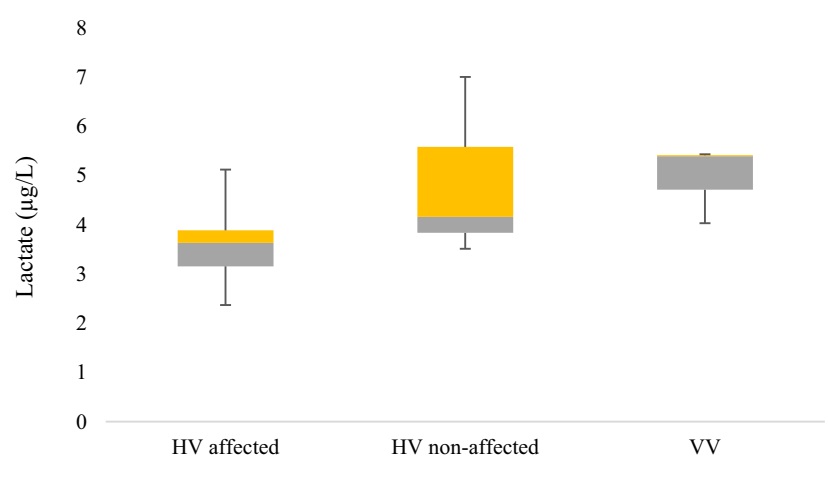

Fig. 4. Boxplot showing lactate levels in the different groups

Table 5. $\mathrm{pH}$, total dissolved solids (TDS) and electric conductivity (EC) values of different water sources

\begin{tabular}{lccc}
\hline Water sample ID & $\mathrm{pH}$ & $\mathrm{TDS}(\mathrm{ppm})$ & $\mathrm{EC}\left(\mu \mathrm{s} / \mathrm{cm}^{-1}\right)$ \\
\hline VV1 & 7.6 & 64 & 129 \\
VV2 & 7.2 & 106 & 211 \\
VV3 & 7.53 & 75 & 151 \\
VV4 & 7.32 & 125 & 251 \\
VV5 & 7.41 & 109 & 219 \\
VV6 & 7.8 & 502 & 1,004 \\
VV7 & 7.61 & 77 & 156 \\
VV8 & 7.35 & 137 & 273 \\
HV1 & 7.4 & 44 & 88 \\
HV2 & 7.42 & 46 & 93 \\
HV3 & 7.16 & 43 & 85 \\
HV4 & 7.09 & 45 & 92 \\
HV5 & 6.9 & 33 & 66 \\
HV6 & 7.29 & 50 & 99 \\
HV7 & 7.34 & 46 & 93 \\
HV8 & 7.63 & 39 & 78 \\
\hline
\end{tabular}

HV: high villages.

VV: valley villages.

glutathione peroxidase activities than animals living in the non-affected regions. Although selenium deficiency is most probably not the single cause of the Transylvanian enzootic equine recurrent rhabdomyolysis syndrome, based on our results it certainly has a major role.

Selenium and vitamin E serve as biological antioxidants: they prevent cellular damage from reactive oxygen species resulting from normal cellular metabolism and counteract negative changes in the skeletal muscles (Aleman, 2008; Radostits et al., 2014; Valberg, 2018). The functions of the two are linked, vitamin $\mathrm{E}$ present in the cell membrane will decrease the formation of lipid peroxides and selenium in the intracellular fluid will remove the lipid peroxides that form (Uttam et al., 2016). There is also another link between selenium and muscle integrity apart from the function of selenium in glutathione peroxidase. Selenium is incorporated in many other selenoproteins and one of these is selenoprotein W which shows the highest expression in skeletal muscle and heart and might be involved in oxidation-reduction reactions. Selenium deficiency is believed to induce muscular degeneration by decreasing the production of selenoprotein $\mathrm{W}$ (Fairweather-Tait et al., 2010). A weak but significant correlation was identified between serum vitamin $\mathrm{E}$ and whole blood selenium concentration. The same observation was noted in a previous study by Streeter et al. (2012). The authors suggested a potential abnormality in the dietary intake of both of these antioxidants which might be a case in our study, as well. Possibly related to no access to fresh green grass, vitamin E level was very low in both groups of horses independently of whether or not they were affected by rhabdomyolysis. The interplay between vitamin $\mathrm{E}$ and glutathione is important for maintaining an appropriate antioxidant balance, and a low daily intake of both might result in more frequent rhabdomyolysis outbreaks (Streeter et al., 2012). On the other hand, vitamin $\mathrm{E}$ has an influence on selenium metabolism as well (NRC, 2007; Uttam et al., 2016).

We demonstrated a negative correlation between GSHPx and AST, and GSH-Px or selenium and lactate levels but not with CK. A probable explanation for this is that low antioxidative capacity might result in chronic muscle damage and thus increased AST and abnormal anaerobe metabolism with increased lactate content. In a previous study, similar results have been found (Streeter et al., 2012). These authors also failed to identify significant associations between selenium status and the muscle enzyme CK, as an indicator of muscle-related damage. Since CK has a relatively short half-life of hours compared to AST of several days, it might indicate chronic muscle damage less reliably since its serum level is rather strongly related to the timing of the exercise (Valberg, 2018).

Table 6. Results of $f$ test, $t$-test and ANOVA evaluating water sources

\begin{tabular}{|c|c|c|c|c|c|c|c|c|c|}
\hline \multirow[b]{2}{*}{ Parameters } & \multicolumn{3}{|c|}{$f$ test } & \multicolumn{3}{|c|}{$\begin{array}{c}T \text {-test two-sample assuming } \\
\text { unequal variances }\end{array}$} & \multicolumn{3}{|r|}{ ANOVA } \\
\hline & $F$ crit. & $F$ cal. & Observation & $T$ crit. & $T$ cal. & Observation & $F$ crit. & $F$ cal. & Observation \\
\hline $\mathrm{pH}$ & 0.26 & 0.73 & Unequal variances & 2.14 & 1.89 & Equal mean & $\begin{array}{c}3.7 \\
5.59\end{array}$ & $\begin{array}{l}0.94 \\
3.49\end{array}$ & No samples and water type dif. \\
\hline TDS & 3.78 & 782 & Unequal variances & 2.36 & 2.07 & Equal mean & $\begin{array}{l}3.78 \\
5.59\end{array}$ & $\begin{array}{l}1.06 \\
4.44\end{array}$ & No samples and water type dif. \\
\hline EC & 3.78 & 762 & Unequal variances & 2.36 & 2.07 & Equal mean & $\begin{array}{l}3.78 \\
5.59\end{array}$ & $\begin{array}{l}1.06 \\
4.44\end{array}$ & No samples and water type dif. \\
\hline
\end{tabular}

TDS: total dissolved solids.

EC: electric conductivity. 
The concentration of selenium in feedstuffs is influenced by variations in soil selenium, $\mathrm{pH}$ and other soil minerals (NRC, 2007). Forages and grains containing less than $0.1 \mathrm{ppm}$ selenium may result in a selenium/vitamin $\mathrm{E}$ deficiency disorder; a much higher incidence of this disorder occurs when the selenium concentration drops below $0.05 \mathrm{ppm}$ (Uttam et al., 2016). All our hay samples originating from the $\mathrm{HV}$ areas had selenium levels below our detection limit of $0.05 \mathrm{ppm}$, while the average selenium content of hay in the VV areas was sufficient but showed high standard deviation. Based on all these data, the daily dietary selenium intake was generally higher in the VV area but still very variable. As described previously, plants grown in poorly aerated, acid soils or soils originating from volcanic rock or soils with a high content of some specific minerals (e.g. iron or sulphur) contain less selenium (Aleman, 2008).

On the one hand we found that the mineral content of soils originating from the $\mathrm{HV}$ areas was higher, resulting in interactions potentially affecting the selenium absorption of plants. On the other hand, the level of selenium in plants depended primarily on the water-soluble selenium content of the soil. It seems that groundwater was washing out watersoluble minerals from the high-area soils towards the valley, which is also reflected in the relatively higher TDS content of the VV water sources. We found generally higher mineral content in the VV hay samples, although the differences were not significant in most cases. Significantly higher iron concentration was detected in the VV hay samples, although this could have limited selenium absorption from the gastrointestinal tract. Also, this was possibly counteracted by the higher selenium availability in the forages. Complex interactions with $\mathrm{S}, \mathrm{Ca}$ and $\mathrm{Cu}$ might also influence the selenium absorption of animals (Uttam et al., 2016).

In the HV area the low selenium content of the hay was reflected by the deficient selenium status of the horses, but in the VV areas, even with very variable daily selenium intake, the horses maintained sufficient serum selenium levels. Hayes et al. (1987) also found that dietary selenium concentrations often do not correlate with blood selenium levels. They concluded that besides interactions with other minerals, breed differences might play a role in the ability to absorb selenium. In humans, a single nucleotide polymorphism in GPx1 (Pro198Leu) was associated with selenium deficiency and impaired GPx1 activity. This observation raised the issue of whether common polymorphisms in selenoprotein genes would have a significant effect on the metabolism of dietary selenium and would generate different bioavailability figures (Fairweather-Tait et al., 2010).

All the horses included in the study, independently of the area, were of a similar breed, although the effect of individual genotype was not examined. All horses had a similar diet and workload. Based on all these, the cause of the difference in serum selenium levels between HV and VV horses was not completely clarified.

Many authors have demonstrated a positive correlation between selenium and GSH-Px in horses (Caple et al., 1978;
Roneus and Lindholm, 1983; Higuchi et al., 1989; Ludvikova et al., 2005a). Vervuert et al. (2000) described a correlation between the activity of GSH-Px in the blood and selenium concentration in the blood plasma using linear regression. The coefficient of correlation determined by them is very low $(r=0.49)$. We found a stronger correlation $(r=0.777)$ between selenium and GSH-Px results. These differences possibly arise from different methodologies as it has also been suggested previously by Maas et al. (1996). Another possibility, based on a previous study by Vervuert et al. (2000) and on our own results, is that the correlation between plasma selenium and GSH-Px is stronger when values are low and animals are deficient. On the other hand, low sample numbers could also influence all study results.

Another aspect of the correlation between selenium and GSH-Px is that serum selenium reflects actual intake and GSH-Px rather reflects the long-term supply. Selenium is incorporated into erythrocytes during erythropoiesis and the activity of GSH-Px is thus regarded as an indicator of longterm selenium status; in contrast, selenium concentration in the whole blood reflects the immediate supply status of the organism (Harris, 1998). In our study, affected horses living in the HV area had low GSH-Px level as opposed to animals in the non-affected region with values in the physiological range reported by most authors (Roneus and Lindholm, 1983; Ludvikova et al., 2005a). According to our results, horses in the HV area had an absolute chronic selenium deficiency since both measurements produced low values.

Nutritional myopathy was associated with glutathione peroxidase values lower than $200 \mu \mathrm{kat} / \mathrm{L}^{-1}$ (Ludvikova et al., 2005a,b) and with serum selenium values lower than $60 \mu \mathrm{g} / \mathrm{L}^{-1}$ (Blackmore et al., 1982; NRC, 2007; Streeter et al., 2012). In the present study, horses living in the affected areas had similarly low mean levels of serum selenium $\left(37.95 \pm 58.22 \mu \mathrm{g} \mathrm{L}^{-1}\right)$ and glutathione peroxidase (119.57 \pm $\left.45.55 \mu \mathrm{g} / \mathrm{L}^{-1}\right)$. On the other hand, Vervuert et al. (2004) reported that Icelandic horses with low plasma selenium had no health problems. When evaluating the correlation between low selenium and myopathies, the level of physical stress should also be considered. A decrease in selenium concentration of the blood is observed in horses used intensively as working hours increase (Wyganowska et al., 2017). Taking into consideration the physical stress, it has been demonstrated previously that selenium deficiencies in horses undergoing intensive training can be critical due to the fact that physical exertion increases the level of reactive oxygen species in the blood (Valberg, 2012). In the horses included in the current study, rhabdomyolysis episodes were more commonly associated with the dramatically increasing workload when forestry works started. Antioxidant deficiency could be tolerated during periods of rest and low exercise intensity but muscle damage by reactive oxygen species became significant during heavy work. On the other hand, foals born in the area were not affected by the typical selenium/vitamin E deficiency syndromes like WMD or equine degenerative myeloencephalopathy (EDM). Even the vitamin $\mathrm{E}$ deficiency-related equine motor neuron disease (EMND) had low prevalence in the area. It is possible that 
foals are protected because pregnant mares have access to pastures and concentrates in the last trimester of gestation which could sufficiently increase their daily selenium and vitamin $\mathrm{E}$ intake. The pregnant mares do not perform heavy work, so antioxidant usage is relatively low in this period.

Although, according to Valberg (2018), low GSH-Px activity and/or selenium concentration are specific to the diagnosis of nutritional myodegeneration, we still need to evaluate the possible role of hereditary myopathies (Delesalle et al., 2017; Valberg, 2018). Both the clinical picture of exertional rhabdomyolysis and the phenotype of the horses increase the possibility of polysaccharide storage myopathies (PSSM) (Delesalle et al., 2017), so genetic tests and muscle biopsies would be needed to fully evaluate the situation (the relevant results will be reported in the second part of this paper). Previously, Valentine (2005) suggested that horses with PSSM and also with selenium or vitamin E deficiency may exhibit more frequent and/or more severe signs of exertional rhabdomyolysis owing to oxidative injury incited by the release of free radicals from damaged muscle cell membranes.

Most of the cases occurred as exercise-induced rhabdomyolysis but in some cases clinical episodes occurred while the horse was resting in the stable, and dysphagia was one of the leading signs. These observations also underline the possible role of selenium deficiency. Myodegeneration of the masseter muscles secondary to antioxidant deficiency could be the explanation, as it was previously described by Ludvikova et al. (2005a). This Transylvanian rhabdomyolysis syndrome seems to have complex underlying causes, and selenium deficiency is only one of them. Also, this reported selenium deficiency might explain some but not all of the cases.

Further myopathies were excluded as follows: atypical myopathy was excluded based on clinical signs, no access to pastures and lack of Acer trees in the surrounding area (González-Medina et al., 2017). Electrolyte loss by sweating and overexertion are both possible causes of sporadic rhabdomyolysis but not of chronic, recurrent cases (Valberg, 2018). Looking back to the past 60 years, it was observed that almost all cases occurred in the two high-lying villages and the problem was rarely reported in the other two villages in the valley, although the horses performed the same work (similar workload in the same surroundings with a similar diet) with the same potential risk of electrolyte loss and overexertion (Kósa et al., 2015, 2018).

Resting muscle enzymes were increased in both groups, although a trend towards higher values could be seen in the $\mathrm{HV}$ horses. This might be caused by the presence of a persistent underlying musculoskeletal problem in both populations of horses, which manifests only in specific circumstances of increased workload and selenium deficiency. When the selenium content of the soil is lower than $0.6 \mathrm{ppm}$, there is a clear risk of low selenium content in the grass, and it has been suggested that it is desirable to control the selenium levels in food and feed crops to a range between 0.1 and $1 \mathrm{ppm}$ (Delesalle et al., 2017). Since both the soil of this area and the forage fed to the affected horses in this study contain low levels of selenium, oral supplementation should be a regular practice. If pasture grazing is not available, then daily vitamin E supplementation in the feed is also advised to prevent deficiency syndromes such as myopathies.

\section{ACKNOWLEDGEMENTS}

The authors would like to thank Dr. Kinga Joó DVM for her contribution in sample collection. The project was supported by the European Union and co-financed by the European Social Fund (grant agreement no. EFOP-3.6.3-VEKOP-162017-00005, project title: 'Strengthening the scientific replacement by supporting the academic workshops and programs of students, developing a mentoring process'). Special thanks are due to Biopol Development and Trading Ltd for its help in testing the water samples.

\section{REFERENCES}

Aleman, M. (2008): A review of equine muscle disorders. Neuromuscul. Disord. 18, 277-287.

Bedford, H. E., Valberg, S. J., Firshman, A. M., Lucio, M., Boyce, M. K. and Trumble, T. N. (2013): Histopathologic findings in the sacrocaudalis dorsalis medialis muscle of horses with vitamin E-responsive muscle atrophy and weakness. J. Am. Vet. Med. Assoc. 242, 1127-1137.

Blackmore, D. J., Campbell, C., Dant, C., Holden, J. E. and Kent, J. E. (1982): Selenium status of thoroughbreds in the United Kingdom. Equine Vet. J. 14, 139-143.

Caple, I. W., Edwards, S. J. A., Forsyth, W. M., Whiteley, P., Selth, R. H. and Fulton, L. J. (1978): Blood glutathione peroxidase activity in horses in relation to muscular dystrophy and selenium nutrition. Aust. Vet. J. 54, 57-60.

Che, H.-L., Meam-Yee Tan, D., Meganathan, P., Gan, Y.-L., Razak, G. A. and Fu, J-Y. (2015): Validation of a HPLC/FLD method for quantification of tocotrienols in human plasma. Int. J. Anal. Chem. 2015, Article ID 357609, https://doi.org/10.1155/2015/ 357609.

Delesalle, C., de Bruijn, M., Wilmink, S., Vandendriessche, H., Mol, G., Boshuizen, B., Plancke, L. and Grinwis, G. (2017): White muscle disease in foals: focus on selenium soil content. A case series. BMC Vet. Res. 13, 121.

Fairweather-Tait, S. J., Collings, R. and Hurst, R. (2010): Selenium bioavailability: current knowledge and future research requirements. Am. J. Clin. Nutr. 91(Suppl.), 1484S-1491S.

Finno, C. J. and Valberg, S. J. (2012): A comparative review of vitamin $\mathrm{E}$ and associated equine disorders. J. Vet. Intern. Med. 26, 1251-1266.

Foreman, J. H., Potter, K. A., Bayly, W. M. and Liggitt, H. D. (1986): Generalized steatitis associated with selenium deficiency and normal vitamin E status in a foal. J. Am. Vet. Med. Assoc. 189, 83-86.

Gomez, D. E., Valberg, S. J., Magdesian, K. G., Hanna, P. E. and Lofstedt, J. (2015): Acquired multiple ACYL-COA 
dehydrogenase deficiency and marked selenium deficiency causing severe rhabdomyolysis in a horse. Can. Vet. J. 56, 11661171.

González-Medina, S., Ireland, J. L., Piercy, R. J., Newton, J. R. and Votion, D. M. (2017): Equine atypical myopathy in the UK: epidemiological characteristics of cases reported from 2011 to 2015 and factors associated with survival. Equine Vet. J. 49, 746-752.

Harris, A. P. (1998): Musculoskeletal disease. In: Reed, S. M. and Bayly, W. M. (eds) Equine Internal Medicine. W. B. Saunders Company, St. Louis. pp. 371-426.

Hayes, J. W., Stiner, C. G., Holmes, M. J. and Mackenzie, S. A. (1987): Comparison of selenium blood levels and dietary selenium in three breeds of horses. Equine Pract. 9, 25-29.

Higuchi, T., Ichijo, S., Osame, S. and Ohishi, H. (1989): Studies on serum selenium and tocopherol in white muscle disease of foal. Nippon. Juigaku Zasshi 51, 52-59.

Janicki, K. M., Lawrence, L. M., Barnes, T. and O'Connor, C. I. (2000): The effect of dietary Se source and level on broodmares and their foals. J. Anim. Sci. 78 (Suppl. 1), 172. (Abstr.).

Kirschvink, N., Moffarts, B. and Lekeux, P. (2008): The oxidant/ antioxidant equilibrium in horses. Vet. J. 177, 178-191.

Kósa, C. A., Szenci, O. and Kutasi, O. (2015): Classification of equine myopathies, description of exercise-induced myopathies with focus on the Transylvanian characteristics [in Hungarian, with English abstract]. Magy. Allatorv. Lapja 137, 451-462.

Kósa, C. A., Mircean, M., Taulescu, M, Turcitu, M., Oana, L., Szenci, O. and Kutasi, O. (2018): Characteristics of exertional rhabdomyolysis in a Szeklerland region: case report [in Hungarian, with English abstract]. Magy. Allatorv. Lapja 140, 643659.

Lofstedt, J. (1997): White muscle disease of foals. Vet. Clin. N. Am. Equine Pract. 13, 169-185.

Ludvikova, E., Jahn, P. and Lukas, Z. (2007): Nutritional myodegeneration as a cause of dysphagia in adult horses: three case reports. Vet. Med. Czech 52, 267-272.

Ludvikova, E., Jahn, P., Pavlata, L. and Vyskocil, M. (2005b): Selenium and vitamin $\mathrm{E}$ status correlated with myopathies of horses in the Czech Republic. Acta Vet. 74, 377-384.

Ludvikova, E., Pavlata, L., Vyskocil, M. and Jahn, P. (2005a): Selenium status of horses in the Czech Republic. Acta Vet. 74, 369-375.

Maas, J., Parish, S. M., Hodgson, D. R. and Valberg, S. J. (1996): Nutritional myopathies. In: Smith, B. P. (ed.) Large Animal
Internal Medicine: Diseases of Horses, Cattle, Sheep, and Goats. Mosby, St. Louis, USA. pp. 1513-1518.

NRC (2007): Nutrient Requirements of Horses. Sixth edition. National Research Council, Washington, DC.

Paglia, D. E. and Valentine, W. N. (1967): Studies on the quantitative and qualitative characterization of erythrocyte glutathione peroxidase. J. Lab. Clin. Med. 70, 158-169.

Radostits, O. M., Gay, C. C., Kenneth, W. H. and Peter, D. C. (2014): Veterinary Medicine. Tenth edition. Saunders Elsevier, Philadelphia.

Roneus, B. and Lindholm, A. (1983): Glutathione peroxidase activity in the blood of healthy horses given different selenium supplementation. Nord. Vet. Med. 35, 337-345.

Streeter, R. M., Divers, T. J., Mittel, L., Korn, A. E. and Wakshlag, J. J. (2012): Selenium deficiency associations with gender, breed, serum vitamin $\mathrm{E}$ and creatine kinase, clinical signs and diagnoses in horses of different age groups: a retrospective examination 1996-2011. Equine Vet. J. 44, 31-35.

Uttam, S., Abioye, F., Dennis, H. and Leticia, S. (2016): Selenium in animal nutrition: deficiencies in soils and forages, requirements, supplementation and toxicity. Int. J. Appl. Agric. Sci. 2, 112125.

Valberg, S. J. (2002): A review of the diagnosis and treatment of rhabdomyolysis in foals. AAEP Proc. 48, 117-121.

Valberg, S. J. (2012): Muscling in on the Cause of Tying-Up. Proceedings of the 58th Annual Convention of the American Association of Equine Practitioners, Anaheim, CA, USA, 58, 85-123.

Valberg, S. J. (2018): Disorders of the musculoskeletal system. In: Reed, S. M., Bayly, W. M. and Sellon D. C. (eds) Equine Internal Medicine. Fourth edition. Saunders, St. Louis, Missouri. pp. 542-579.

Valentine, B. A. (2005): Diagnosis and treatment of equine polysaccharide storage myopathy. J. Equine Vet. Sci. 25, 52-61.

Vervuert, I., Coenen, M. and Braun, S. (2004): Feeding management of Icelandic horses in Iceland and after importation in Germany with emphasis on selenium supply - first communication (in German). Pferdeheilkunde 20, 23-29.

Vervuert, I., Coenen, M., Holtershinken, M., Venner, M. and Rust, P. (2000): Assessment of selenium status in horses - new aspects. Tierarztl. Prax. G. N. 28, 172-177.

Wyganowska, A., Górski, K., Jania, B., Danielewicz, A. and Andraszek, K. (2017): The effect of selenium on proper body function in horses. J. Anim. Plant Sci. 27, 1448-1453. 